\title{
O PROFESSOR DE BIOLOGIA EM FORMAÇÃO: REFLEXÃO COM BASE NO PERFIL SOCIOECONÔMICO E PERSPECTIVAS DE LICENCIANDOS DE UMA UNIVERSIDADE PÚBLICA
}

\author{
Pre-service Biology teacher training: reflection \\ based on public university future teachers' \\ socio-economical profile and professional perspectives
}

\author{
Simão Dias Vasconcelos ${ }^{1}$ \\ Kênio Erithon Cavalcante Lima ${ }^{2}$
}

\begin{abstract}
Resumo: Esta pesquisa buscou investigar o perfil socioeconômico de licenciandos em Ciências Biológicas, suas motivações para escolher o curso e suas perspectivas quanto ao seu futuro profissional. Observou-se que a maioria dos estudantes trabalha, é proveniente de escola pública, tem baixo hábito de leitura e pretende seguir carreira de pesquisador. A maioria afirma ter escolhido Licenciatura por vocação, embora revele baixíssimo interesse pela pesquisa em ensino de Biologia como área de atuação profissional. Os licenciandos, de modo geral, estão satisfeitos com o curso e acreditam que a formação recebida na universidade contribuirá significativamente para sua empregabilidade.

Palavras-chave: Formação inicial de professores de Biologia. Expectativa profissional de licenciandos em Biologia. Pesquisa em Ensino de Biologia.
\end{abstract}

\begin{abstract}
This research aimed to investigate future Biology teachers' socio-economical profile, their motivations for choosing the program and perspectives regarding their professional future. We noticed that most of the future teachers work, come from public High School, have low reading custom, and intend to follow a Biology researcher career. Most of them declare to have chosen the program based on vocation, although reveal very low interest in Biology Education research as professional carrier. The majority of them is satisfied with the undergraduate program they are taking and believe that their training in the university will help significantly for their employment.
\end{abstract}

Keywords: Future Biology teachers training. Biology teachers' socio-economical profile. Biology teaching research.

\footnotetext{
${ }^{1}$ Engenheiro Agrônomo, doutor em Zoologia. Docente, Departamento de Zoologia, Centro de Ciências Biológicas, Universidade Federal de Pernambuco (UFPE). Recife, PE, Brasil. <simao@ufpe.br>

${ }^{2}$ Licenciado em Ciências Biológicas, mestre em Ensino das Ciências. Docente, Centro Acadêmico de Vitória, UFPE. Vitória de Santo Antão, PE, Brasil. <keclima@ig.com.br>
}

\footnotetext{
${ }^{1}$ Laboratório de Ensino de Zoologia, Centro de Ciências Biológicas, UFPE.

Avenida Professor Moraes Rego, s/n

Cidade Universitária - Recife, PE

$50.670-420$

323

Ciência \&̊ Educação, v. 16, n. 2, p. 323-340, 2010
} 
Vasconcelos, S. M.; Lima, K. E. C.

\section{Introdução}

\section{A “crise” no ensino de Ciências e a formação do licenciando}

Nos últimos anos, o Brasil vem alcançando posições constrangedoras em pesquisas mundiais sobre o nível de conhecimento sobre Ciências entre alunos do Ensino Básico avaliados no Programa Internacional de Avaliação de Estudantes (PISA) da Organização para Cooperação e Desenvolvimento Econômico (OECD, 2006). Tais resultados representam uma ferida na imagem da educação nacional e enfatizam a necessidade de se repensarem os cursos de Licenciatura para melhorar o ensino das Ciências nos diferentes níveis. Uma visão geral das causas deste fenômeno engloba diversos fatores, entre os quais se destacam: indisciplina escolar, baixa remuneração e/ou motivação dos professores, limitada estrutura escolar, políticas flexíveis de aprovação, fraca motivação de alunos e docentes, ineficiências na gestão escolar e aspectos socioeconômicos da população atendida pelo ensino público. Diversos questionamentos surgem como desdobramentos desta situação:

A realidade da educação brasileira, com superlotação nas salas de aula, desvalorização do profissional, e defasada estrutura física, metodológica e didática nas escolas instiga o docente a (se) questionar: "como" fazer e "com que" fazer educação, adequando-se à proposta projetada pelos parâmetros curriculares e pelo mercado de trabalho? Afinal, as escolas - especialmente da rede pública - constituem-se de alunos marcantemente heterogêneos cultural e socialmente, o que requer do professor de Ciências o uso equilibrado de conceitos, de técnicas (competências) adequadas à comunidade; e dos seus instintos de educador (habilidades). (LIMA e VASCONCELOS, 2006, p.399)

Por outro lado, a ampliação da escolaridade registrada nos últimos anos no Brasil gera novos - e mais complexos - desafios para o professor recém-egresso de um curso de Licenciatura. Professores de ciências são elementos-chave nas mudanças dos indicadores negativos do nosso ensino: além de trabalharem o conteúdo, atuam ativamente como mediadores no processo de inclusão científica e tecnológica dos cidadãos, contribuindo para aproximar as ciências do cotidiano do estudante.

A formação do licenciando em Ciências reproduz valores assimilados na vida pessoal e escolar. Isto porque, além da bagagem acadêmica, sua formação é constituída por saberes experienciais que refletem diversas relações inerentes à profissão; combinados, os saberes experienciais e disciplinares habilitam o docente a resolver problemas em seu campo de ensino (TARDIF, 2004). Especificamente, a formação acadêmica oferecida precisa capacitá-lo a superar e responder às representações de mundo presentes na sociedade atual diante das novas descobertas científicas e dos avanços tecnológicos.

Considerando que alunos de Licenciatura frequentemente chegam à universidade com lacunas em sua formação teórico-prática, amplia-se a responsabilidade das universidades em proporcionar igualdade de conhecimento, aprofundamento intelectual e oportunidade para os futuros professores. Especialmente porque: 
O professor de Biologia em formação: reflexões ...

A construção de professores críticos e reflexivos, de intelectuais engajados e capacitados para a construção da cidadania na sala de aula é desafio emergente e imprescindível em qualquer tentativa consequente de transformação da escola. Favorecer, incentivar, estudar e/ou provocar as condições para que este desenvolvimento ocorra, capacitando os professores para enfrentar estes desafios, é tarefa a que a universidade não pode (mais) se furtar. (DIAS-DA-SILVA, 1998, p. 6)

\section{A responsabilidade dos cursos de Licenciatura em Ciências}

Apesar de reconhecer o papel dos demais componentes humanos no processo de ensino-aprendizagem, cabe ao professor a maior parte da responsabilidade em relação à diretriz metodológica a ser adotada: um ensino repetidor de fórmulas e conceitos, em que o aluno assume uma postura passiva, ou uma abordagem transformadora, contextualizada e questionadora, na qual o sujeito é estimulado a assumir postura crítica e participativa? Estudos comprovam que o principal diferenciador da qualidade do ensino não é a estrutura física da escola, nem acesso a recursos de informática e, nem mesmo, a classe socioeconômica do aluno, mas, sim, a capacidade do docente para estimular a curiosidade cientifica e a participação dos alunos (INSTITUTO NACIONAL DE ESTUDOS E PESQUISAS EDUCACIONAIS ANÍSIO TEIXEIRA - INEP, 2001).

Licenciaturas desempenham papel vital no desenvolvimento da sociedade, ao formarem pessoas autônomas na busca do saber, que extrapolem a mera competência técnica e visem à formação integral do ser humano, formando profissionais com um espírito de constante interrogação a respeito do mundo, do homem, da cultura, da educação e da escola, e buscando, ainda, ampliar a reflexão sobre o mundo (COELHO, 2006).

Nesse processo, as instituições de Ensino Superior (IES) incorporam recursos e saberes às representações sobre a natureza da ciência, suas atitudes e simbologias didáticas vividas na formação escolar, ao transmitirem conhecimentos e procedimentos, resgatados junto aos saberes experienciais. Nas IES resgatam-se o percurso de vida, os saberes e anseios dos futuros professores, que os caracterizam pessoal e profissionalmente, compreendendo suas expectativas após a graduação. Acabam, assim, por cumprir papéis que deveriam ter sido desempenhados pelo Ensino Básico, como: o estímulo à leitura, a familiarização com os princípios básicos da metodologia científica e o domínio dos recursos da informática.

Dados do Censo Superior de Educação revelam um gradativo aumento no número de estudantes matriculados em cursos de licenciaturas no Brasil, superando os 100.000 estudantes a partir de 2004 (BRITO, 2007), especialmente no horário noturno. Barreiro e Terribili Filho destacam alguns indicadores sobre o curso noturno:

Uma outra característica da educação superior no Brasil é a de que há 2.454.348 matrículas no período noturno, representando $58,9 \%$ do total, percentual crescente a cada ano. Deste montante, $82,7 \%$ das matrículas (2.029.054) está nas instituições privadas, o que representa que em cada dez estudantes do período noturno da educação superior no país, oito deles estão em instituições privadas. (BARREIRO e TERRIBILI FILHO, 2007, p. 85) 
Vasconcelos, S. M.; Lima, K. E. C.

Recentes propostas de reformulação no ensino público superior almejam ampliar a oferta de cursos e matrículas de graduação no turno noturno, em parte para ocupar espaços ociosos e absorver alunos que precisam trabalhar no período diurno. Problemas práticos como a dificuldade de realização de aulas em laboratório, excursões a campo e outras atividades extraclasse, baixa disponibilidade e falta de interesse de docentes, além de limitada infraestrutura disponível e insegurança nos campi - detectados em licenciaturas (VASCONCELOS, 2000), comprometem iniciativas formais de ampliação dos cursos noturnos.

Apesar dessa importância, curiosamente, poucos estudos investigam a origem e a formação inicial do professor, ou como suas visões e escolhas profissionais se confrontam com suas expectativas de trabalho e de demanda para o ensino de ciências no Brasil. Em muitos casos, licenciaturas ainda são expostas à noção disseminada de que formar bacharéis, futuros pesquisadores, reveste-se de maior importância do que formar professores (BRITO, 2007).

\section{Delineamento da pesquisa}

Respondendo aos anseios dos Parâmetros Curriculares Nacionais, "PCN+ e OCEM para o ensino de Biologia", Lei de Diretrizes e Bases e outras normativas reguladoras de sua atividade profissional, o professor embasado no conhecimento pedagógico-científico construído na vida escolar, social e acadêmica deve organizar as diversas estratégias metodológicas adquiridas para o fortalecimento da relação ensino-aprendizagem com seus alunos, promovendo uma formação resultante de valores escolar, social, familiar, acadêmico e profissional (BRASIL, 1996, 1999, 2002, 2006).

A Região Nordeste enfrenta uma situação paradoxal no ensino de ciências. Ao mesmo tempo em que suas escolas do Ensino Básico apresentam desempenho sofrível em avaliações de compreensão de leitura e conteúdo científico, a região oferece uma abundância de cursos de licenciatura em Ciências e só perde para a Região Sudeste em número de estudantes matriculados em licenciaturas (BRITO, 2007), além de contar com vários cursos de pós-graduação em ensino de Ciências. O estado de Pernambuco, por sua vez, possui desde centros de excelência a escolas que ostentam os piores indicadores do ensino de $5^{a}$ a $8^{a}$ séries do país, com índice médio de 2,354 em uma escala de 1 a 5, e uma das piores distorções idade-série, segundo dados do Índice de Desenvolvimento da Educação Básica/SAEB (2005) (INEP, 2007).

Partindo da concepção de que a formação do futuro professor mistura e acumula experiências prévias ao seu ingresso na universidade e é influenciada tanto por aspectos socioeconômicos e intelectuais quanto por suas motivações e expectativas em relação ao curso, propusemo-nos a ampliar a discussão sobre a identidade do licenciando em Ciências Biológicas de uma universidade pública. Especificamente, buscamos analisar: o perfil do licenciando, sua formação prévia, suas motivações para escolher a licenciatura, e suas perspectivas quanto à vida profissional, incluindo seu futuro envolvimento na carreira de pesquisa em ensino. $\mathrm{O}$ conhecimento obtido com esta pesquisa pode contribuir para estimular ações nas IES, com reflexos na atuação docente do professor de ciências no Ensino Básico, superando algumas defasagens na formação desses licenciandos. 
O professor de Biologia em formação: reflexões ...

\section{Metodologia}

\section{Caracterização do curso}

O curso de Licenciatura em Ciências Biológicas da Universidade Federal de Pernambuco (UFPE) foi criado em 1996, a partir do desmembramento de um curso que apresentava dois perfis (Bacharelado e Licenciatura em Ciências Biológicas). Considerando a subutilização da infraestrutura local, o curso se propõe a atender à demanda de alunos que desejem estudar à noite, sobretudo por necessidade de consorciar com o trabalho no período diurno. Compõese de oito períodos, integrando disciplinas pedagógicas com as de conceitos específicos em Biologia. Atualmente, o curso passa por reformas na estrutura curricular, o que, em breve, determinará um novo perfil. Na época da pesquisa, havia 200 alunos regularmente matriculados, segundo a coordenação do curso.

\section{Coleta de dados}

A pesquisa foi realizada nos meses de março e abril de 2002, tendo como públicoalvo estudantes de Licenciatura em Ciências Biológicas regularmente matriculados entre o primeiro e o oitavo período. Os questionários foram aplicados a 130 estudantes $(65 \%$ do universo) nos diversos prédios onde as aulas eram ministradas, a fim de se cobrir, ao máximo, o perfil de estudantes iniciantes e concluintes. O elevado índice de evasão e repetência entre os alunos, e a possibilidade de cumprir disciplinas de diversos semestres simultaneamente impediu a classificação do aluno como "típico" de determinado semestre.

O questionário baseou-se em dois eixos temáticos: a) perfil socioeconômico do estudante e b) expectativas em relação ao curso e perspectivas profissionais. As perguntas enfocaram: questionamentos sobre a origem escolar, formação superior prévia, renda familiar, grau de instrução dos pais, acesso a veículos de informação, hábito de leitura, perspectivas em relação ao curso e à formação continuada, contribuição do curso em sua empregabilidade e planos de pós-graduação. Ao final, foi deixado espaço para comentários dos alunos. Houve tempo livre para a resolução dos questionários e o anonimato dos respondentes foi mantido para garantir fidedignidade das respostas.

\section{Resultados e discussão}

\section{Educação básica e ingresso na Licenciatura}

O perfil dos licenciandos revela que 56,2\% concluíram o Ensino Médio em escolas públicas, comparados a 43,8\% oriundos de escolas particulares (Tabela 1). Este padrão difere do observado anteriormente no mesmo curso por Vasconcelos (2000), que registrou maior proporção de licenciandos egressos da rede particular (58\%). Isto pode ser interpretado sob diferentes ângulos; um ponto positivo e detectado na interação direta com os alunos é a maior inserção de egressos da rede pública, ampliando a função social da universidade federal. No 
Vasconcelos, S. M.; Lima, K. E. C.

estudo de Brito (2007), a proporção de licenciandos egressos de escolas públicas analisados foi de $68,2 \%$, valor superior ao encontrado neste trabalho. Na Universidade Federal de Minas Gerais, o percentual de ex-alunos da rede pública também é superior ao dos egressos de escolas particulares, atingindo 90\% em 1996 (PARREIRAS e PEREIRA, 2000).

Estudos recentes (MARQUES e PEREIRA, 2002) atribuem a menor procura por cursos de licenciatura aos menores status social, remuneração e competitividade da profissão quando comparados a cursos de Bacharelado, por exemplo. Por ser um curso de aprovação mais "fácil", a procura pode ser maior por parte dos candidatos que não se consideram aptos a concorrerem para cursos mais competitivos. Por exemplo, no vestibular de 2008 das universidades federais de Pernambuco, o número de candidatos por vaga para o curso de Licenciatura em Ciências Biológicas da UFPE esteve entre os mais baixos (2,9 candidatos/vaga) dentre os mais de sessenta cursos oferecidos pela instituição em Recife. Neste contexto, a procura dos alunos da rede privada por cursos tradicionalmente voltados à elite socioeconômica que opta por profissões mais bem remuneradas (Direito e Medicina são alguns exemplos), de certa forma, oportuniza as licenciaturas para egressos da escola pública.

Uma explicação adicional é a contribuição de programas de cunho social que visam qualificar vestibulandos provindos de instituições públicas, como o Programa Professores do Terceiro Milênio, descrito por Vasconcelos e Lima (2004). Esse programa destina-se a exalunos de escolas públicas que desejem realizar vestibular para licenciatura e necessitam qualificar a aprendizagem, aumentando sua competitividade por uma vaga nas universidades envolvidas: UFPE e UFRPE (Universidade Federal Rural de Pernambuco). Graças ao projeto, houve aumento no preenchimento de vagas nas licenciaturas por ex-alunos do programa, com alta aprovação dos beneficiados, inclusive com excelentes médias no vestibular.

\section{Vínculo empregatício e motivações para cursar Licenciatura}

Observou-se que 9,2\% dos licenciandos consultados já haviam concluído um curso superior não correlato à atividade de ensino (Tabela 1); porém, foram motivados a fazer outro curso pela necessidade de titulação específica para atividades de ensino, por já atuarem nesse campo de trabalho.

Cerca de $65 \%$ dos licenciandos em Biologia ingressaram via vestibular; os demais foram provenientes de transferências de cursos internos e externos à instituição, ou ingressaram como portador de diploma (Tabela 1). Dos que tentaram vestibular, 69,4\% optaram por Licenciatura como uma "segunda opção", após terem tentado aprovação em outros cursos, dos quais se destacam Medicina (38,8\%), Odontologia (14,1\%), Farmácia (8,5\%) e Biomedicina $(8,5 \%)$. A visão da licenciatura como uma "segunda escolha" também pareceu ocorrer entre licenciandos da Universidade Estadual de Maringá (PR); a proporção de estudantes que tinham Ciências Biológicas como primeira opção não ultrapassava 30\% naquela instituição (MARICATO et al., 2002).

Cerca de $70 \%$ dos licenciandos trabalham durante o período diurno, dos quais apenas 40,4\% atuam diretamente em educação (Tabela 1). Os números refletem a realidade da UFPE, pois, no convívio direto com os estudantes, percebemos que muitos não articulam o conteúdo trabalhado na universidade diretamente em seu local de trabalho, por ocuparem funções diversas (serviços, vendas, telemarketing e assistência técnica foram as ocupações mais citadas). O 
O professor de Biologia em formação: reflexões ...

percentual desses alunos que trabalham é bastante elevado; apenas para comparação, é mais do que o dobro do observado entre os licenciandos da Universidade Federal do Piauí (30,7\%) (SALES e LOPES, 2006). Entretanto, dados sobre perfil de licenciandos, analisados por Brito (2007), revelam que mais de $80 \%$ estão envolvidos em atividade profissional.

Os desafios para o estudante que trabalha incluem desde a menor disponibilidade de tempo para realização de estágios e pesquisas até questões mais pragmáticas, como problemas diários no trânsito e transporte, implicando atrasos e perdas de aulas, conforme enfatizam Terribili Filho e Raphael (2005).

Tabela 1. Perfil geral de licenciados em Ciências Biológicas, UFPE, quanto à formação básica, vínculo empregatício e expectativas profissionais após graduação.

\begin{tabular}{lcc}
\hline & & \\
\hline Ingresso na universidade & SIM) & NÃO (\%) \\
$\quad$ Concluiu os estudos em escola pública? & 56,2 & 43,8 \\
$\quad$ O ingresso no Curso foi via Vestibular? & 63,8 & 36,2 \\
$\quad$ Já possui curso superior? & 9,2 & 90,8 \\
Experiência profissional & 72,3 & 23,1 \\
$\quad$ Trabalha no período diurno?* & 40,4 & 59,6 \\
Caso trabalhe, na área de educação? & 90,0 & 10,0 \\
Expectativas profissionais & 17,7 & 82,3 \\
Deseja fazer pós-graduação após concluir a Licenciatura? & 88,5 & 11,5 \\
Deseja fazer pós-graduação em ensino de Ciências Biológicas? & 60,8 & 30,8 \\
Você acredita que conseguirá emprego em sua área? & & \\
Se pudesse optar, preferiria trabalhar somente em pesquisa biológica?** & & \\
\hline
\end{tabular}

*Não respondeu: 4,6\%; **Não respondeu: 8,4\%.

Quando questionados sobre a motivação para ingressar na Licenciatura, a resposta mais frequente $(45,4 \%)$, para os que optaram por licenciatura como primeiro curso, foi o interesse em lecionar por vocação, por se sentirem realizados em buscar a profissão que realmente desejam exercer (Tabela 2). Outra justificativa frequente foi a busca da regulamentação da atividade docente entre os que já ensinavam em situação "não-oficial", como bacharéis em Biologia que lecionam no Ensino Básico, o que não é permitido de acordo com a LDB. Outro grupo de alunos buscava a titulação acadêmica como ferramenta para promoção em seus respectivos empregos. Essas categorias encontram paralelo nas respostas detectadas no ENADE (BRITO, 2007), variando desde o desejo de ser professor, a mais significante $(54,8 \%)$, à proximidade da IES à residência do aluno ( $3,7 \%$ das respostas).

Em concordância com recentes estudos que confirmam o efeito positivo da escolaridade na renda do indivíduo, os resultados revelam o desejo de muitos licenciandos de mudarem de atividade profissional, algumas distintas da área de educação, como é o caso de concursos públicos em áreas administrativas, bastante citado de forma espontânea. Para outros alunos, a licenciatura representa uma opção mais "cômoda" pelo fato de ser um vestibular menos concorrido (2,9 candidato/vaga, comparado, por exemplo, a 4,5 candidato/vaga no curso de Bacharelado em Ciências Biológicas) ou por ter horário conveniente, conciliando o curso com outras atividades que já exerciam (Tabela 2). 
Vasconcelos, S. M.; Lima, K. E. C.

Tabela 2. Categorias que relatam as razões pela opção do curso de Licenciatura em Ciências Biológicas da UFPE. Mais de uma opção possível.

\begin{tabular}{lc}
\hline \multicolumn{1}{c}{ Categoria } & $\%$ \\
\hline Pretendo ensinar/tenho vocação & 45,4 \\
O horário era mais conveniente & 31,5 \\
Já exerço a profissão e desejo aprofundar conhecimento & 12,3 \\
A concorrência era menor & 11,5 \\
Facilidade de transferência para outro curso da área de saúde & 7,7 \\
Necessito qualquer título superior & 2,3 \\
\hline
\end{tabular}

O fato de nem todos os egressos de um curso superior atuarem no mercado de trabalho pertinente é relativamente comum entre estudantes de cursos de baixa remuneração. Entretanto, não deixa de ser preocupante a ocupação de vagas por alunos sem interesse direto na docência. Este aparente descaso pode gerar concluintes com limitadas perspectivas profissionais, aumentando a evasão e a distorção entre período e disciplina, os indicadores mais negativos dos cursos noturnos. A falta de identificação com o curso pode ainda resultar na formação de profissionais insatisfeitos e de menor competência na docência no nível básico. Estudantes desmotivados, sem perspectivas de empregarem diretamente em seu trabalho o que aprendem na universidade, obstaculizam seu compromisso com o processo de ensino-aprendizagem. As consequências negativas desta postura serão sentidas pelos alunos do nível básico - o que em parte explica os baixos rendimentos obtidos por estudantes brasileiros em sistemas formais de avaliação sobre alfabetização científica, como o PISA, anteriormente citado.

\section{Formação dos pais e renda familiar dos licenciandos}

Ao se investigar o grau de instrução dos pais dos licenciandos, observa-se uma formação variável, desde o Ensino Fundamental incompleto até curso superior completo (Fig. 1). A maioria dos pais enquadra-se na categoria "Ensino Médio", que, quando somada à do Ensino Fundamental, corresponde a mais de 70\%. Em comparação, a maioria dos licenciandos em Biologia da UFMG possui pais cujo nível de instrução é o do Ensino Fundamental incompleto (PARREIRAS e PEREIRA, 2000). Já no perfil analisado por Brito (2007), cerca de 58\% dos licenciandos apresentam pai e mãe com escolaridade mínima de Ensino Fundamental.

Corazza-Nunes et al. (2002) destacam que licenciandos cujos pais tinham instrução de Ensino Médio ou Superior (78,0\%, no caso dos estudantes da Universidade Estadual de Maringá) optam por cursos diurnos, diferindo de licenciandos cujos pais possuem apenas Ensino Fundamental e Médio, os quais tendem a optar pelo turno noturno. Essa relação pode ser parcialmente explicada porque alunos de famílias com renda mais baixa veem-se obrigados a consorciar estudos com trabalho para aumentar a renda familiar. Estudos sobre a participação dos pais - especialmente das mães - na formação acadêmica dos filhos revelam evidentes resultados positivos para o melhor desempenho, com estímulos à formação educacional e profissional dos filhos (TARDIF e RAYMOND, 2000; SALES e LOPES, 2006). 


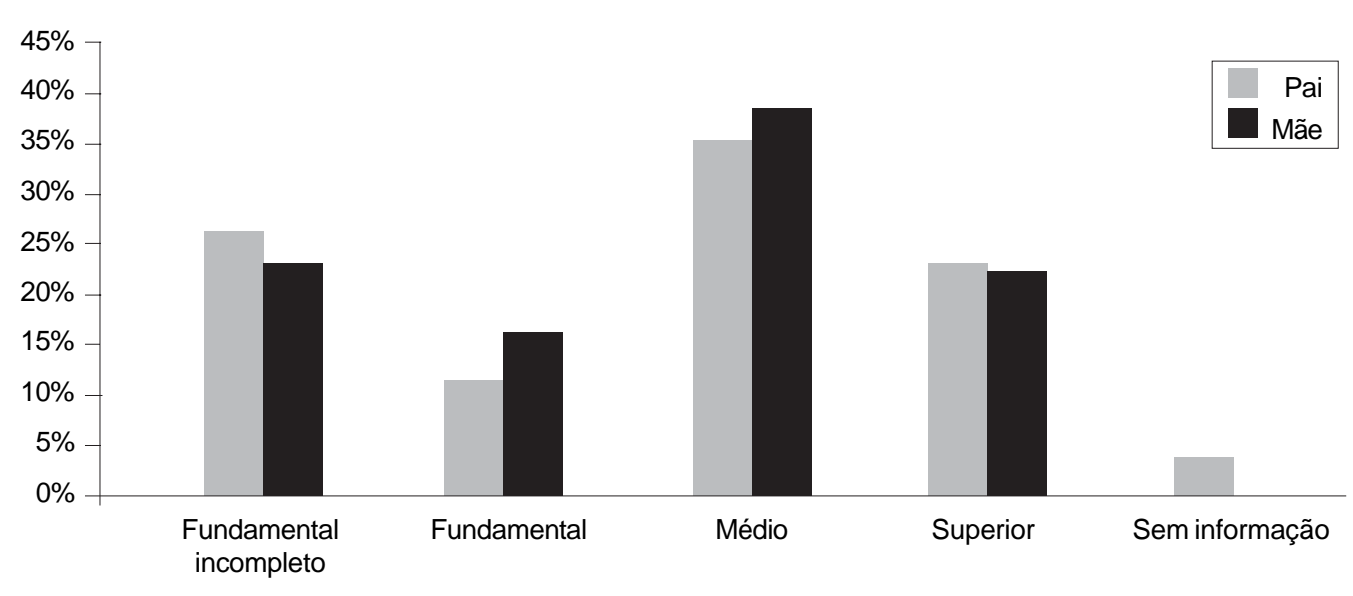

Figura 1. Nível de formação dos pais dos licenciandos em Biologia da UFPE.

Quanto à renda familiar, a faixa mais comum dentre as famílias dos licenciandos de Ciências Biológicas da UFPE situa-se em torno de cinco a dez salários-mínimos (SM) (Figura 2), um perfil de renda que pode ser considerado como de classe média. Um padrão semelhante foi observado por Parreiras e Pereira (2000) entre licenciandos em Biologia da UFMG. Já Corazza-Nunes et al. (2002) observaram diferenças na renda familiar entre licenciandos de Maringá, relatando que os de curso diurno apresentam entre três e quatro SM, e os de curso noturno, com média de dois SM, um perfil econômico bem inferior ao observado neste trabalho. $\mathrm{Na}$ análise de Brito (2007), cerca de 50\% dos licenciandos têm renda familiar entre três e dez SM, dos quais muitos trabalham quarenta horas semanais, fenômeno também detectado em nosso estudo.

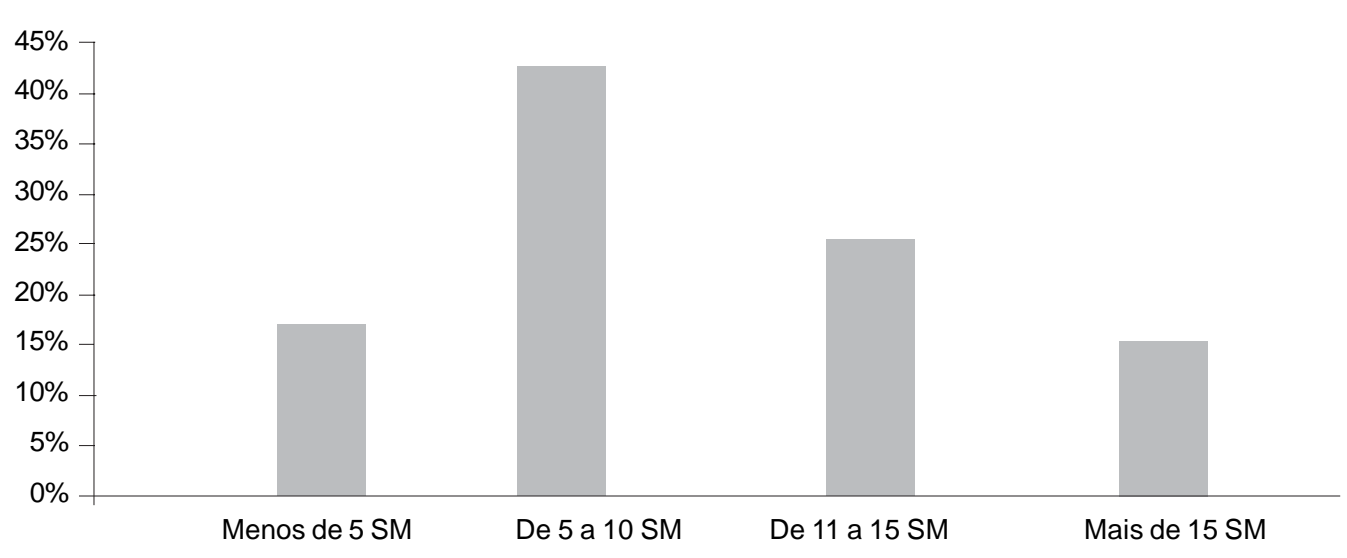

Figura 2. Renda familiar dos licenciandos em Biologia da UFPE (SM = salários-mínimos). 
Em geral, jovens com maior poder aquisitivo podem optar por cursos de maior concorrência ou maior status social, e, por não precisarem trabalhar, têm maiores condições de se dedicarem integralmente aos estudos, incluindo a realização de estágios e participação em eventos científicos fora do horário de aula. Estudos recentes (MACHADO e GONZAGA, 2007) comprovam uma relação positiva entre renda e nível de instrução dos pais com aspectos da escolaridade dos filhos, como o nível de instrução, o qual é frequentemente superior ao dos pais. A defasagem série-idade também tende a ser menor à medida que aumenta a instrução do pai e da mãe (MACHADO e GONZAGA, 2007).

\section{Fontes de informação e leitura do licenciando}

Ao se investigar a formação intelectual dos estudantes, especialmente sobre as fontes de informação às quais têm acesso e/ou usam, observamos que $83 \%$ utilizam os noticiários de televisão aberta, $76 \%$ o rádio e $75 \%$ os jornais de circulação local para se manterem atualizados "de modo geral", isto é, tanto sobre Ciências como sobre acontecimentos atuais. Internet e livros técnicos são proporcionalmente menos utilizados (Figura 3). A baixa frequência de consulta a livros e textos científicos na internet surpreende por serem recursos indispensáveis para a formação intelectual e profissional do futuro professor. Os licenciandos que afirmam usar a internet acessam-na, sobretudo: em suas residências (49\%), na universidade (42\%) e no trabalho $(40 \%)$. A relativa subutilização da internet pode ser um reflexo do desconhecimento de ferramentas e sites que permitam realizar revisões bibliográficas, e dificulta o aprofundamento do conteúdo visto em sala de aula, especialmente em periódicos científicos indexados com acesso livre.

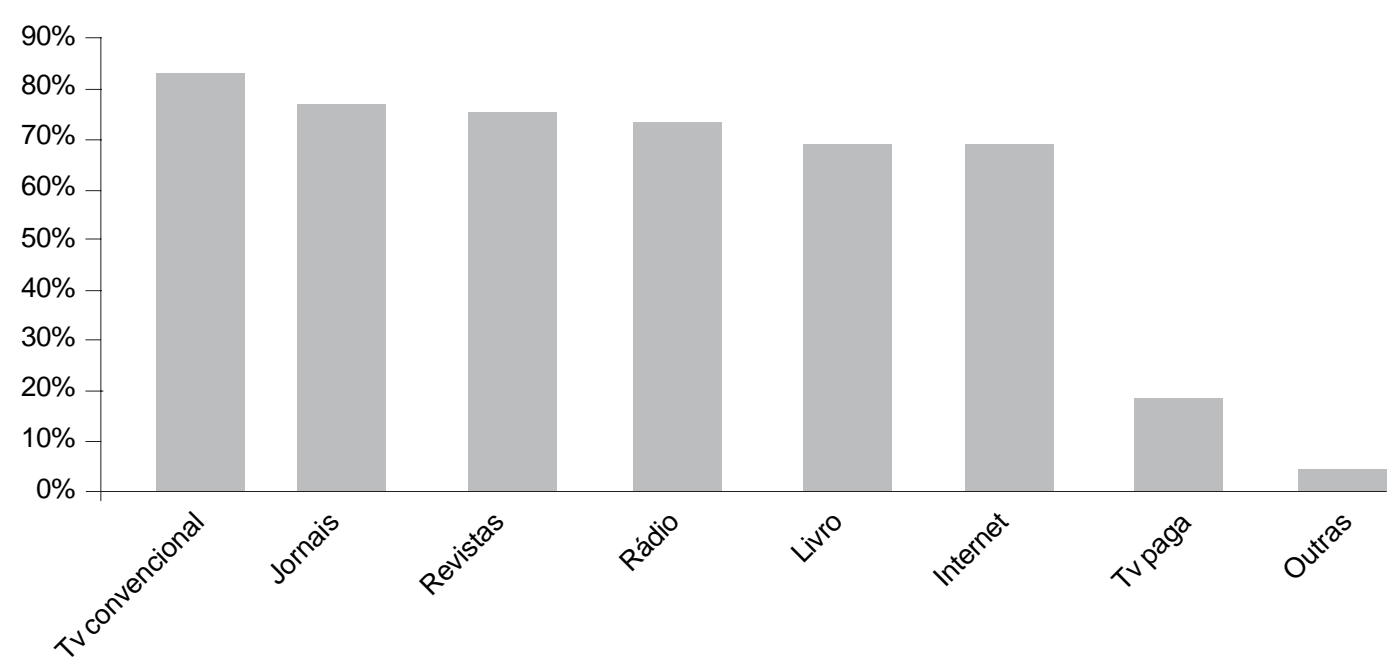

Figura 3. Principais fontes de informação dos licenciandos em Biologia da UFPE. Mais de uma resposta possível. 
O professor de Biologia em formação: reflexões ...

Quanto ao hábito da leitura, pouco mais de 40\% dos licenciandos afirmam ler mais de quatro livros/ano (Figura 4). São valores baixos, confirmando resultados recentes do ENADE (BRITO, 2007), que revelam dados preocupantes: apenas um terço dos universitários brasileiros lê mais de dois livros por ano - valores desprezíveis quando comparados a outros países. Reafirmando a significância desse hábito, Teixeira Jr. e Silva (2007, p. 1365) ressaltam que "pensar na leitura na formação inicial de professores constitui uma necessidade inadiável e, pessoalmente, como desafio premente na condição de professores na disciplina de Prática de Ensino".

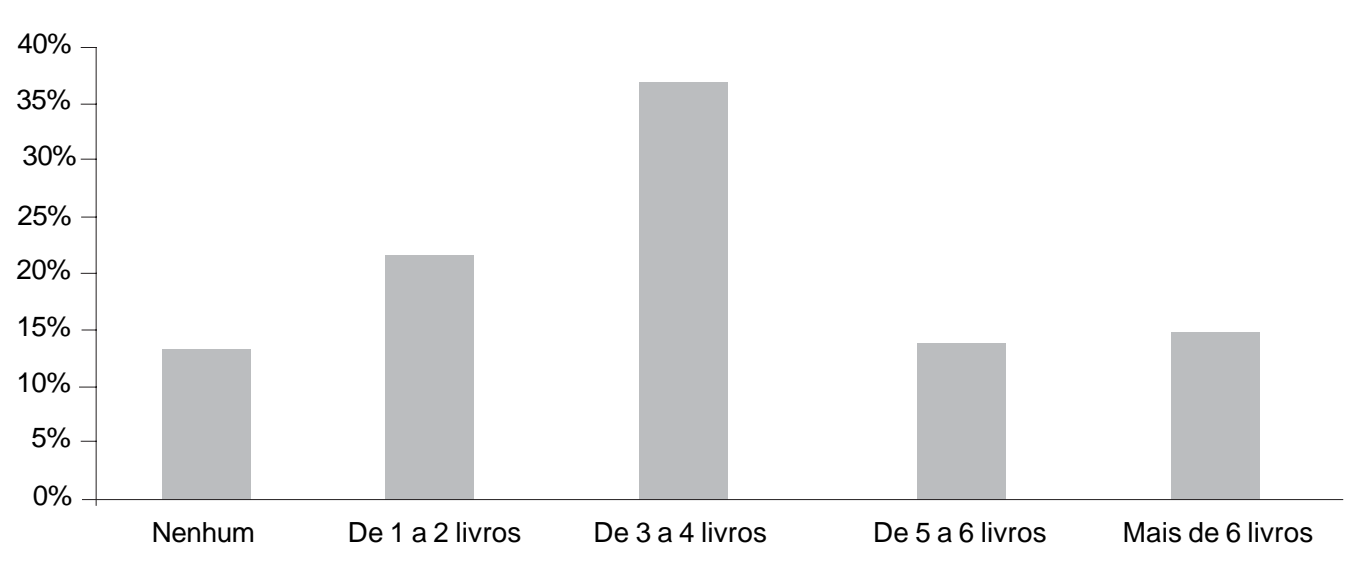

Figura 4. Quantitativo de livros lidos espontaneamente, por ano, pelos licenciandos em Biologia da UFPE.

Por mais que se atribua essa atitude ao custo dos livros, há outras variáveis envolvidas, como: a falta de estímulo à leitura no ambiente familiar e a crescente dependência da televisão - e, nos últimos anos, de sites na internet - como fontes de informação e lazer. Considerando que as diversas formas de acesso a informações e o hábito da leitura contribuem na formação intelectual e social de graduandos, a baixa frequência de leitura, entre licenciandos da UFPE, compromete a ampliação de formas de pensar e se expressar, características cruciais ao futuro professor. Sendo papel da leitura promover constante atualização de conhecimentos, fundamental nas diversas profissões, seu exercício é indispensável para a assimilação e discussão de temas atuais, na sala de aula, pelo professor.

\section{A importância da formação continuada}

Questionados sobre as perspectivas profissionais, 90,0\% dos estudantes desejam fazer pós-graduação, demonstrando valorização da formação continuada e de uma maior qualificação profissional (Tabela 1). Contudo, apenas 17,7\% pretendem fazer Mestrado e Doutorado na área de ensino/educação sobre o processo de ensino-aprendizagem em Ciências Bioló- 
Vasconcelos, S. M.; Lima, K. E. C.

gicas. Os estudantes demonstram maior interesse por pesquisas em áreas de conhecimentos específicos, vinculando-se a grupos de pesquisa sobre Genética, Ecologia e Zoologia - os mais citados. Muitos desses licenciandos desconhecem programas de pós-graduação em áreas fora do conteúdo estritamente biológico, pois houve inexpressível citação espontânea $(1,5 \%)$ de cursos de pós-graduação na área de Educação/ Ensino de Ciências, corroborando estudos preliminares de Vasconcelos (2000). Atualmente, não existem grupos de pesquisas na área de Ensino das Ciências/Biologia no Centro de Ciências Biológicas da UFPE, fato que dificulta ao licenciando conhecer e se interessar por pesquisas em linha de conhecimento aplicadas a esta área. Algumas opiniões extraídas deste trabalho ilustram bem tanto a falta de conhecimento como de interesse em seguir carreira de "pesquisador em ensino de Ciências":

"É obrigação do curso de Licenciatura divulgar possibilidades de pesquisa em Educação. A gente mesmo não fica sabendo de nada, só por acaso". (estudante do $4^{\circ}$ período)

"Nunca ouvi falar de nenhum curso de Mestrado ou Doutorado que fizesse pesquisa sobre Ensino de Biologia". (estudante do $4^{\circ}$ período)

"Para que me especializar em ensino de Biologia se eu sei que os projetos financiados é (sic) tudo na área de pesquisa de ponta, como biologia molecular, engenharia genética e ecologia?'” (estudante do $6^{\circ}$ período)

"Eu até gosto de mexer com metodologias de ensino, experimentação, essas coisas, mas se eu seguir essa área, só vou poder ser professora, enquanto se eu me especializar em Genética eu vou poder ser tanto professora como pesquisadora". (estudante do $5^{\circ}$ período)

O insuficiente interesse de licenciandos das Ciências Biológicas em seguir carreira de pesquisador em Ensino de Ciências/Biologia pode, a médio prazo, refletir negativamente para a qualidade do Ensino Básico no Estado. Ora, se os futuros docentes valorizam (muito) mais o conteúdo específico, frequentemente de modo pontual e isolado da realidade da sala de aula, em detrimento ao conteúdo pedagógico, então sua formação para docência reproduz equívocos ainda encontrados na universidade. Será que os professores envolvidos na formação deste licenciando efetivamente criam, testam e estabelecem metodologias de ensino e avaliação de Ciências/Biologia como parte fundamental das competências do professor-pesquisador? Seria a propalada "baixa qualidade de ensino de Ciências" apenas mais um reflexo do desvio de formação dos professores de aspectos pedagógicos metodológicos do ensinar para a priorização de aspectos meramente conteudistas? É possível crer que os futuros docentes recebem, em sua formação, a compreensão de que a sala de aula é um laboratório de investigação de sua própria prática pedagógica, e que sua visão de cientista deve impregnar sua atividade docente?

A aparente indiferença por parte dos licenciandos em apreender, de forma questionadora, concepções pedagógicas que favoreçam o ensino-aprendizagem durante a graduação irá, no futuro, se traduzir em limitações para a aplicação de metodologias inovadoras em situações reais no Ensino Básico. A consequência óbvia é a persistência, na sala de aula, de uma baixa 
O professor de Biologia em formação: reflexões ...

diversidade metodológica, comprometendo a inter-relação ensino-aprendizagem no ensino básico. Sendo o exercício da prática cotidiana um termômetro da aplicação de saberes docentes assimilados e em formação (TARDIF, 2004), o professor deve almejar a renovação e aperfeiçoamento da prática resultante de sua experiência, de suas concepções de educador para gerar aprendizagem significativa com seus alunos, tendo em mente que suas práticas pedagógicas bem-sucedidas são fruto de uma criteriosa pesquisa.

Compreende-se, a partir daí, a necessidade do licenciando/professor de entender a graduação e a formação continuada como processos dinâmicos de constante atualização em sua vida acadêmica, viabilizando sua atuação como mediador de conhecimentos. Para isso, é fundamental discutirem conceitos/concepções que serão aplicados e embasados nas novas tecnologias para adequá-las aos interesses da sociedade. Apesar disto, muitos licenciandos da UFPE ainda não se dedicam a atividades de atualização científica, um padrão semelhante ao perfil desenhado por Brito (2007), no qual 54,9\% dos estudantes desconheciam ou não participavam de atividades de pesquisa durante a graduação.

\section{Perspectivas profissionais}

De acordo com os resultados desta pesquisa, que parecem caracterizar a opção pelo ensino como "secundária", não surpreende o fato de que o percentual de licenciandos que preferiria trabalhar em pesquisa $(62 \%)$ é praticamente o mesmo dos que prefeririam atuar com ensino (61\%), sendo superiores a outras atividades como atividades produtivas, indústrias, órgãos ambientais e/ou consultoria (Figura 5). Isso fortalece nossa percepção de que há um certo conflito entre o que os estudantes afirmam ser sua vocação (o ensino) e o que eles afirmam ser sua principal meta (pesquisa e ensino). Ainda que a atividade docente esteja entre as principais metas, ao se priorizar também a pesquisa infere-se que, para boa parte dos licenciandos, o exercício em sala de aula do Ensino Básico é considerado uma atividade de menor reconhecimento social, como pode ser percebido na fala transcrita a seguir:

"Eu já dou aula e tenho a maior satisfação em ensinar no ensino fundamental. Mas seria hipocrisia dizer que minha meta não é ser pesquisador da Federal [UFPE], pois ganha bem mais e tem muito mais reconbecimento". (estudante do $6^{\circ}$ período)

É possível que o plano inicial de muitos licenciandos fosse a docência no nível básico. Porém, o contato com a vida acadêmica, com grupos de pesquisa distantes de estudos pedagógicos pode tê-los estimulado a mudanças atitudinais. O curso habilita-os a trabalhar tanto em pesquisa como em atividades não-acadêmicas (consultorias, produção animal e vegetal, laboratórios, indústrias etc.), além das atividades pedagógicas - sendo visível, ao longo da formação universitária, o valor superior relegado à pesquisa na área biológica dentre os que fazem a universidade pública. Maior status ao professor doutor, elevada (em alguns casos, excessiva) valoração da produção de artigos em revistas científicas de nível "A", valorização do currículo com base em congressos científicos nos programas de pós-graduação do Centro de Ciências Biológicas da UFPE, são apenas algumas das faces de um mosaico complexo que distancia o licenciando cada vez mais de seu propósito original: ensinar. 


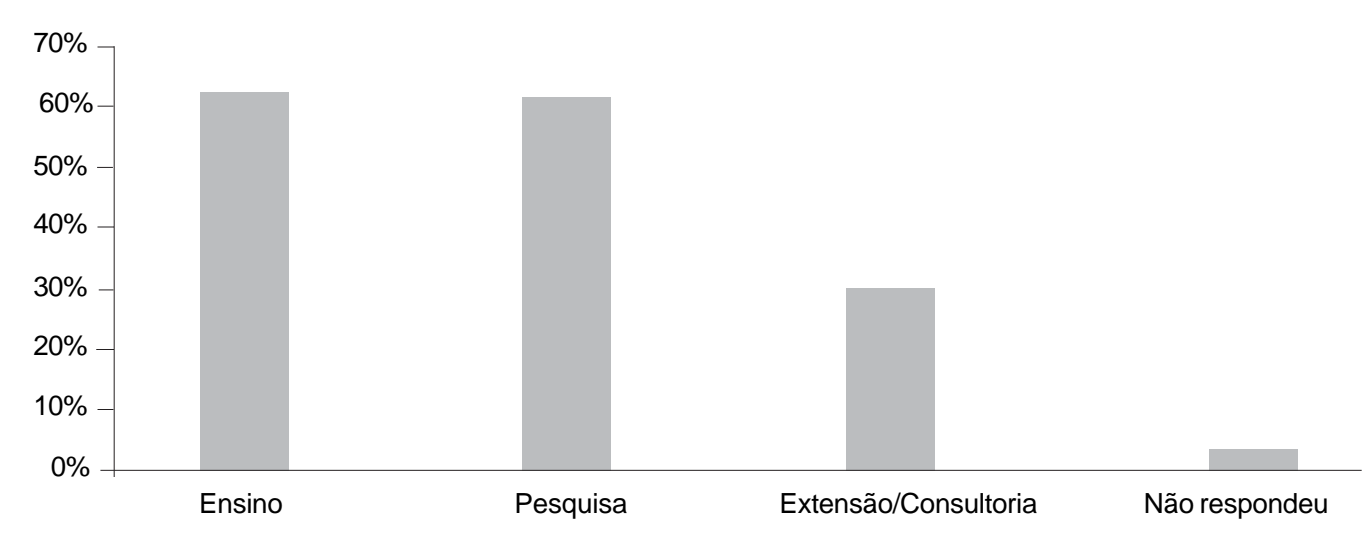

Figura 5. Áreas de atuação nas quais os licenciandos em Biologia da UFPE pretendem trabalhar após a graduação (mais de uma opção possível).

Romero (1997) descreve concepções sobre a profissão de professor, as quais incluem: o fato de ser identificada como uma atividade tipicamente feminina; considerada uma atividade profissional inferior às demais, levando-se em conta o tratamento social, legal, institucional e econômico que recebe; e, não menos importante, destaca o caráter de ascensão social que a profissão assume, ao habilitar pessoas provenientes de classes sociais menos favorecidas. Em um estudo realizado por Brando e Caldeira (2009), também se observou que formandos em Licenciatura em Ciências Biológicas de uma universidade pública de São Paulo aferiam um status superior à atividade laboratorial (associada à pesquisa) quando comparada à atividade docente. Curiosamente, naquele estudo, a atividade de professor era mais frequentemente associada à ideia de "vocação" e, também, ligada a fortes componentes emocionais, evidenciados pelo sentimento de cuidado e ajuda ao próximo que a profissão docente despertava (BRANDO e CALDEIRA, 2009, p.168).

Ao se discutir o perfil de licenciandos, há necessidade de se compreender como estes vislumbram sua absorção no mercado de trabalho - confrontando expectativas e perspectivas. Percebe-se otimismo entre os estudantes: $88,5 \%$ acreditam que conseguirão emprego em suas áreas após a graduação (Tabela 1). Tal entusiasmo não surpreende, pois nos últimos concursos para professores das redes públicas municipais e estadual, egressos da licenciatura da UFPE frequentemente ocuparam a maior proporção das vagas (dados não publicados). Percebe-se, com isso, que a formação do licenciado prepara-o, se não tão bem quanto se gostaria, ao menos em condições de corresponder às necessidades imediatas do mercado de trabalho. Este otimismo é revelado em algumas falas (mas a compreensão de que haveria algo "melhor" a seguir não deixa de ser preocupante):

"Sei que minha formação não é a melhor possivel, mas me prepara o suficiente para conseguir um emprego como professor, depois posso me especializar e buscar algo melhor". (estudante do $3^{\circ}$ período) 
O professor de Biologia em formação: reflexões ...

Dentre os que pretendem seguir pós-graduação (Mestrado e Doutorado), em busca da carreira de pesquisador, as respostas espontâneas sobre a área de atuação estão descritas na Tabela 3. Percebe-se um predomínio de preferência por áreas específicas da Biologia, como Ecologia, Genética e Zoologia (Tabela 3). Esta preferência pode resultar de diversas influências, incluindo o crescente espaço que temas relacionados à Ecologia, Biotecnologia e Genética ocupam na mídia - aliado ao fato de estes temas serem facilmente reconhecidos como "aplicados" - e, também, à existência de pesquisadores de reconhecido nível internacional envolvidos em cursos de mestrado e doutorado nessas áreas na UFPE. A carreira de pesquisador em detrimento da de professor ainda atrai uma significativa parcela dos licenciandos: quase $40 \%$ optariam por trabalhar apenas em pesquisa, "abandonando" a docência se tivessem oportunidade.

Tabela 3. Áreas do conhecimento mais citadas, pelos licenciandos em Biologia da UFPE, para a realização de mestrado e doutorado. Respostas espontâneas, alguns alunos citaram mais de uma opção.

\begin{tabular}{lrr}
\hline \multicolumn{1}{c}{ Área de conhecimento } & N & \multicolumn{1}{c}{$\%$} \\
\hline Ecologia & 76 & 58,5 \\
Zoologia & 60 & 46,2 \\
Genética & 56 & 43,1 \\
Botânica & 48 & 36,9 \\
Biotecnologia & 37 & 28,5 \\
Educação Ambiental & 30 & 23,1 \\
Ensino de Biologia & $\mathbf{2}$ & $\mathbf{1 , 5}$ \\
Outros & 23 & 17,7 \\
\hline
\end{tabular}

Por último, questionamos a avaliação dos licenciandos em relação à qualidade da formação acadêmica recebida. Novamente, percebe-se otimismo e satisfação: 59,7\% dos licenciandos declaram estarem "satisfeitos" ou "muito satisfeitos" com o curso, ao contrário de apenas 15,3\% que afirmam estarem "insatisfeitos". Além disso, 63,1\% dos estudantes acreditam que o curso vai melhorar, $18,5 \%$ acham que vai permanecer no nível em que se encontra e apenas $5 \%$ acreditam que o curso irá piorar nos próximos cinco anos.

Universidades, centros de excelência, são fundamentais na criação dos referenciais teórico-práticos que servirão de base aos profissionais responsáveis pela formação de estudantes da educação básica, atendendo às expectativas sociais. Educadores respondem aos anseios da sociedade com visão que atenda, dentre outros pressupostos, a uma:

abertura e sensibilidade para identificar as relações que existem entre os conteúdos do ensino e das situações de aprendizagem e os muitos contextos de vida social e pessoal, de modo a estabelecer uma relação ativa entre o aluno e o objeto do conhecimento e a desenvolver a capa- 
Vasconcelos, S. M.; Lima, K. E. C.

cidade de relacionar o aprendido com o observado, a teoria com suas conseqüências e aplicações práticas. (BRASIL, 1999, p. 87)

A atualização do professor deve ser permanente, especialmente em um contexto no qual a sociedade confronta valores e questionamentos gerados por avanços tecnológicos. Do professor, exigem-se respostas imediatas, atualizações e mudanças conceituais para acompanhar a evolução no conteúdo teórico, na abordagem e na terminologia dos assuntos referentes à Biologia.

\section{Considerações finais}

Os cursos de Licenciatura em Ciências Biológicas no Brasil vêm passando por profundas mudanças em sua estrutura curricular e diretrizes metodológicas, buscando melhor adequação ao mercado de trabalho do graduado e às novas abordagens educacionais. As recentes mudanças no perfil do licenciando incorporam aspectos positivos, como: uma ampliação da participação de alunos egressos de escolas públicas, um interesse crescente em continuar seus estudos, prosseguindo no Mestrado e Doutorado, e uma satisfação em ensinar - apesar de almejarem prioritariamente o ensino em cursos superiores.

Há, contudo, aspectos preocupantes. O primeiro deles reflete um profundo desconhecimento sobre pesquisa em ensino de Biologia - e suas implicações práticas para um melhor desempenho em sala de aula. Em segundo lugar, percebe-se uma falta de interesse sobre possibilidades de pesquisas na área de ensino de Biologia na região. Para citar exemplos, o licenciado tem a sua disposição, somente em Recife, três cursos de Mestrado nos quais pode explorar o ensino como tema: o Mestrado em Ensino de Ciências da UFRPE, e os mestrados em Educação e em Educação Matemática e Tecnológica, ambos do Centro de Educação da UFPE. Até mesmo mestrados em ciências "duras" podem incorporar projetos multidisciplinares nos quais o conteúdo "específico", como Botânica, Genética ou Anatomia, pode ser abordado sob o ponto de vista pedagógico. Dissertações recentes no Mestrado em Biologia Animal da UFPE, por exemplo, abordaram tópicos como Ensino de Zoologia e Ensino de Filogenia Animal.

Percebe-se, ainda que, de modo indireto, há uma visão equivocada, entre parte dos licenciandos, de que "pesquisar" reveste-se de maior valor do que "ensinar", e que seria uma "promoção" passar de professor a pesquisador. Diferenças de salário, reconhecimento e status à parte, é provável que os alunos sintam menos "orgulho" em serem docentes do Ensino Básico quando comparado a outras atividades exercidas tradicionalmente por bacharéis em Biologia.

Para um curso que se propõe a formar educadores-pesquisadores, é uma situação crítica. O círculo vicioso em que parece se encontrar a pesquisa em ensino de Biologia poucos interessados x baixa visibilidade e reconhecimento das escassas pesquisas existentes dificulta o fortalecimento desta área, quando comparada a grupos mais bem estruturados no Brasil nas áreas de educação em Matemática, Física e Química. Com base na reflexão sobre o diagnóstico apresentado aqui, conclui-se que a construção de uma licenciatura socialmente comprometida, que diminua o abismo entre faz̧er ciência e ensinar ciência, é ainda um desafio dos cursos de formação de professores no Brasil, especialmente no Nordeste. 
O professor de Biologia em formação: reflexões ...

\section{Referências}

BARREIRO, I. M. F.; TERRIBILI FILHO, A. Educação superior no período noturno no Brasil: políticas, intenções e omissões. Ensaio: Avaliação e Políticas Públicas em Educação, Rio de Janeiro, v. 15, n. 54, p. 81-102, 2007.

BRANDO, F. R.; CALDEIRA, A. M. A. Investigação sobre a identidade profissional em alunos de Licenciatura em Ciências Biológicas. Ciência e Educação, Bauru, v. 15, n. 1, p. $155-173,2009$.

BRASIL. MEC. Federação Brasileira, Lei no 9.394, de 20 de dezembro de 1996. Lei de Diretrizes e Bases. Disponível em: <http://www.mec.gov.br>. Acesso em: 10 out. 2007.

Parâmetros Curriculares Nacionais (PCN): Ensino Médio. Brasília: Ministério da Educação, 1999. Disponível em: <http://www.mec.gov.br>. Acesso em: 10 out. 2007.

PCN + Ensino Médio: orientações educacionais complementares aos Parâmetros Curriculares Nacionais. Brasília: MEC, 2002. Disponível em: <http:/www.mec.gov.br>. Acesso em: 10 out. 2007.

Orientações Curriculares para o Ensino Médio: Ciências da Natureza, Matemática e suas Tecnologias (OCEM). Brasília: MEC, 2006. Disponível em: <http://www.mec.gov.br>. Acesso em: 2 dez. 2007.

BRITO, M. R. F. ENADE 2005: perfil, desempenho e razão da opção dos estudantes pelas Licenciaturas. Avaliação, São Paulo, v. 12, n. 3, p. 401-443, 2007.

COELHO, I. M. Universidade e formação de professores. In: GUIMARÃES, V. S. (Org.).

Formar para o mercado ou para a autonomia? O papel da universidade. Campinas: Papirus, 2006. p. 43-63.

CORAZZA-NUNES, M. J.; BENEDITO-CECÍLIO, E.; LANSAC-TÔHA, F. A.; MARICATO, F. E.; MULATI, J. C. Caracterização social, econômica e cultural dos acadêmicos do curso de ciências biológicas da Universidade Estadual de Maringá, PR. In: ENCONTRO "PERSPECTIVAS DO ENSINO DE BIOLOGIA”, 8., 2002, São Paulo. Anais... São Paulo: USP, 2002. 1 cd-rom.

DIAS-DA-SILVA, M. H. G. F. O professor e seu desenvolvimento profissional: superando a concepção do algoz incompetente. Caderno CEDES, Campinas, v. 19, n. 44, p. 33-45, 1998.

INEP. Instituto Nacional de Estudos e Pesquisas Educacionais Anísio Teixeira. Escolas públicas se destacam pela qualidade no ensino. Brasília: MEC, 2001. Disponível em: <http://www.inep.gov.br>. Acesso em: 12 dez. 2007.

SAEB - 2005 primeiros resultados: médias de desempenho do SAEB/2005 em perspectiva comparada. Brasília: MEC, 2007. Disponível em: <http://www.inep.gov.br>. Acesso em: 10 nov. 2007.

LIMA, K. E. C.; VASCONCELOS, S. D. Análise da metodologia de ensino de ciências nas escolas da rede municipal de Recife. Ensaio: Avaliação e Políticas Públicas em Educação, Rio de Janeiro, v. 14, n. 52, p. 397-412, 2006. 
Vasconcelos, S. M.; Lima, K. E. C.

MACHADO, D. C.; GONZAGA, G. O impacto dos fatores familiares sobre a defasagem idade-série de crianças no Brasil. Revista Brasileira de Economia, Rio de Janeiro, v. 61, n. 4, p. 449-476, 2007.

MARICATO, F. E.; BENEDITO-CECÍLIO, E.; LANSAC-TÔHA, F. A.; CORAZZANUNES, M. J.; MULATI, J. C. O porquê da escolha do curso de Ciências Biológicas e as perspectivas profissionais, segundo os acadêmicos da UEM. In: ENCONTRO "PERSPECTIVAS DO ENSINO DE BIOLOGIA", 8., 2002, São Paulo. Anais... São Paulo: USP, 2002. 1 cd-rom.

MARQUES, C. A.; PEREIRA, J. E. D. Fóruns das licenciaturas em universidades brasileiras: construindo alternativas para a formação inicial de professores. Educação e Sociedade, Campinas, v. 23, n. 78, p. 171-183, 2002.

OECD. Panorama da Educação: indicadores da OCDE. Edição 2006. Disponível em: <http://www.inep.gov.br/download/internacional/pisa/PISA2006>. Acesso em: 26 fev. 2008.

PARREIRAS, M. M. M.; PEREIRA, J. E. D. Análise do perfil de licenciatura do curso de Ciências Biológicas (noturno) da UFMG (1994-1999). In: ENCONTRO "PERSPECTIVAS DO ENSINO DE BIOLOGIA", 7., 2000, São Paulo. Anais... São Paulo: USP, 2000. p. 411-423.

ROMERO, D. M. F. Tornar-se professor: reflexões sobre a construção da identidade profissional do professor do curso de magistério. Interações: estudos e pesquisas em Psicologia, São Paulo, v. 2, n. 3, p. 35-46, 1997.

SALES, L. C.; LOPES, A. P. C. Muito merecimento, pouca valorização: representações sociais de licenciandos sobre a docência. In: REUNIÃO ANUAL DA ASSOCIAÇÃO NACIONAL DE PÓS-GRADUAÇÃO E PESQUISA EM EDUCAÇÃO, 27., 2004, Caxambu. Anais... Caxambu: ANPED, 2004. Disponível em: < http://www.anped.org.br/ 27/gt14/p142>. Acesso em: 06 jul. 2006.

TARDIF, M. Saberes docentes e formação profissional. 2. ed. Petrópolis: Vozes, 2004.

TARDIF, M.; RAYMOND, D. Saberes, tempo e aprendizagem do trabalho no magistério. Educação e Sociedade, Campinas, v. 21, n. 73, p. 209-244, 2000.

TEIXEIRA JR., J. G.; SILVA, R. M. G. Perfil de leitores em um curso de Licenciatura em Química. Química Nova, São Paulo, v. 5, n. 30, p. 1365-1368, 2007.

TERRIBILI FILHO, A.; RAPHAEL, H. S. Fatores de atrasos e faltas do estudante do ensino superior noturno: a perda de aulas, de provas e o impacto no seu aproveitamento e em avaliações. Avaliação, Campinas, v. 10, n. 2, p. 117-135, 2005.

VASCONCELOS, S. D. Re-estruturação do curso de Licenciatura em Ciências Biológicas (UFPE): identificação do perfil do aluno. In: ENCONTRO "PERSPECTIVAS DO ENSINO DE BIOLOGIA", 7., 2000, São Paulo. Anais... São Paulo: USP, 2000. p. 341-345.

VASCONCELOS, S. D.; LIMA, K. E. C. Inclusão social e acesso às universidades públicas: o programa "Professores do Terceiro Milênio". Estudos em Avaliação Educacional, Rio de Janeiro, v. 29, n. 1, p. 67-86, 2004.

Artigo recebido em março de 2009 e aceito em abril de 2010. 